\title{
STATISTICAL ANALYSIS OF A COMPANY'S REVENUE USING TIME SERIES
}

\section{Alexandru-Eugen Stătescu ${ }^{1}$}

\begin{abstract}
Economic and financial analysis is a method of knowing the mechanism of formation and modification of the economic phenomena through their decomposition into their component elements and by identifying the factors of influence. The object of the decomposition into elements or factors may be a result (structural analysis), or a change in the result from a basis of comparison (causal analysis).

Revenue is the inflow of economic benefits during the reporting period resulted in the ordinary activity of the company as assets increase or decrease in debt that build equity excluding gains from property company contributions.

The purpose of this paper is to analyze, using statistical research methods, the evolution of the income of a state owned company. For this it will be used the data from the Income and Expense Budget of METROREX S.A. on a 10-year horizon. In order to analyze the time evolution of the enterprise's revenue, it will be used the chronological series analysis methodology, the set of data from the mentioned source (namely the Income and Expense Budget of METROREX SA) and will design an econometric model with a trend and residual variable component.

Time series is a form of orderly presentation of statistical data which reflect the manifestation of phenomena in a given moment or time. In other words, the time series is a sequence of values of an economic indicator or other observed over time, reflecting the process of change and development of a statistical sample in successive periods of time.

Also the purpose of this paper is to build an ARMA model that fits in an appropriate way the evolution of the revenue's time series.
\end{abstract}

JEL Classification Number: C32; DOI: http://dx.doi.org/10.12955/cbup.v6.1198

Keywords: Financial and economic analysis, Revenue, Time series, Adjustment function, Adjusting the model parameters

\section{Introduction}

Income and expenses are not equal to each other, and as a result, there is a change in the volume of the property, a change that is reflected in the accounting through the result of the year (profit or loss).

Information provided by accounting on the profitability and performance of an enterprise is useful in anticipating the ability of an enterprise to generate cash flows with existing resources. They are also useful for making judgments about the efficiency with which the enterprise can use the new resources.

The balance sheet presents assets, liabilities and equity on the basis of which the financial position of an enterprise is measured. The Profit and Loss Account (Income Statement) presents the income and expenses on the basis of which the enterprise's performance is measured.

The general framework defines the expenses and revenues as follows:

- Expenditure is a decrease in the economic benefits recorded during the accounting period in the form of asset write-offs or decreases, which result in reductions in equity other than those resulting from their distribution to shareholders.

- Revenues are increases in the economic benefits recorded during the accounting period in the form of inflows or increases of assets or decreases in debt, which result in increases in equity other than those resulting from shareholder contributions.

\section{Time series. Stationarity. Statistical tests}

The present paper proposes to analyze, using statistical research methods, the evolution in time of the revenues of a state owned company. For this it will be used the data from the Income and Expense Budget of METROREX S.A. on a 10-year horizon. In order to analyze the time evolution of the enterprise's revenue, it will be used the chronological series analysis methodology, the dataset being from the mentioned source (i.e. the Income and Expenses Budget of METROREX S.A.).

A chronological series is a form of orderly presentation of statistical data that reflects the level of manifestation of phenomena at a given time or period of time. In other words, the chronological series is a series of values of an economic or other indicator, observed over time, mirroring the process of changing and developing a statistical collectivity over successive periods of time.

The general form of a chronological series can be as follows:

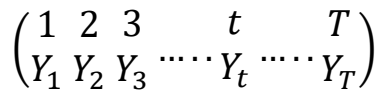

\footnotetext{
${ }^{1}$ Bucharest University of Economic Studies, Economic Cybernetics and Statistics Doctoral School, alexandrustatescu@yahoo.com
} 
where:

$t=$ time or time interval $(t=1, T)$;

$y_{t}=$ the level (expressed by absolute or relative data) reached by the $Y$ phenomenon at time $t$.

The statistical description of the time series starts from the analysis of the factors causing their movement. Generally, the evolution of a phenomenon is generated by the action of some groups of factors:

- the essential factors with long-lasting action, which implies the trend of their evolution; the action of these factors being studied according to the time units for which the phenomenon analyzed was measured;

- seasonal factors, for periods of less than one year, which lead to deviations from the trend of the phenomenon imprinted by the essential factors;

- cyclical factors, with effects over periods of more than one year, which imply an oscillating evolution of the phenomenon in the case of long-time series;

- Random factors (random action), the action of which is compensated if the recorded data refers to a large number of periods of time. Starting from the structure of the factors that determine the evolution of a phenomenon, the statistical description of the time series can be made using the following models:

1. Addition models

$$
y_{t}=f(t)+s(t)+c(t)+u(t)
$$

2. Multiplicative models

$$
y t=f(t) \cdot s(t) \cdot c(t) \cdot u(t)
$$

where:

$f(t)=$ the trend component, the effect of the action of the key factors;

$s(t)=$ seasonal component, effect of seasonal factors action;

$c(t)=$ the cyclical component generated by the action of cyclic factors;

$u(t)=$ the residual component, which expresses the influence of the random factors on the evolution of the phenomenon.

A time series $y_{t}$ is stationary if:

$-E\left(y_{t}\right)=\bar{y}, \forall t=\overline{1, T}$

time;

$-\operatorname{var}\left(y_{t}\right)=\sigma_{y}^{2}=$ constant,$\forall t=\overline{1, n}$

(3.4) the dispersion of the series is time independent;

- $\operatorname{Cov}\left(y_{t}, y_{t+k}\right)=$ constant $, \forall t=\overline{1, n}, k<n$ (3.5) the covariance of the series does not depend on time. The definition above is the definition of weak stationarity. A series of time is therefore stationary if its media, dispersion and covariance remain constant over time. If any of the above conditions is not satisfied, then the time series is non-stationary.

If the first two conditions above cannot be accepted, but $\operatorname{Cov}\left(y_{t}, y_{t+k}\right)=\rho(k), \forall t=\overline{1, n}, k<n$ (3.10), where $\rho(k)$ represents the $k$-autocorrelation function, then the assumption of weak stationarity can be accepted.

The time series $\left\{\varepsilon_{t}\right\}_{t=\overline{1, T}}$ consisting of randomly uncorrelated variables, respectively:

$-E\left(\varepsilon_{t}\right)=0, \forall t=\overline{1, T}$

$-\operatorname{var}\left(\varepsilon_{t}\right)=\sigma_{\varepsilon}^{2}, \forall t=\overline{1, n}$

$-\operatorname{Cov}\left(\varepsilon_{t}, \varepsilon_{p}\right)=0, \forall t, p=\overline{1, T}, t \neq p$

is called the white noise.

This series is stationary with the autocovariance function: $\rho(k)=\left\{\begin{array}{c}\sigma^{2}, k=0 \\ 0, \text { otherwise }\end{array}\right.$

and the autocorrelation function $r(k)=\left\{\begin{array}{c}1, k=0 \\ 0, \text { otherwise }\end{array}\right.$.

It is noted $W N\left(0, \sigma^{2}\right)$ the white noise, namely $\left\{\varepsilon_{t}\right\}_{t=\overline{1, T}} \approx W N\left(0, \sigma^{2}\right)$. 
The time series $\left\{y_{t}\right\}_{t=\overline{1, T}}$, where $y_{t}=\varepsilon_{t}-\gamma \cdot \varepsilon_{t-1}, \gamma \neq 0$ and $\left\{\varepsilon_{t}\right\}_{t=\overline{1, T}} \approx W N\left(0, \sigma^{2}\right)$, is called the first-order moving average $M A(1)$, it is noted $\left\{y_{t}\right\}_{t=\overline{1, T}} \approx M A(1)$. This series is stationary for any $\gamma \neq$ 0 , has the mean 0 and the autocovariance function: $\rho(k)=\left\{\begin{array}{c}\left(1+\gamma^{2}\right) \cdot \sigma^{2}, k=0 \\ -\gamma^{2} \cdot \sigma^{2}, k= \pm 1 \\ 0, \text { otherwise }\end{array}\right.$ and autocorrelation function $(k)=\left\{\begin{array}{l}1, k=0 \\ -\frac{\gamma}{1+\gamma^{2}}, k= \pm 1 \\ 0, \text { otherwise }\end{array}\right.$

In analyzing time series, most of these are non-stationary.

A time series $\left\{y_{t}\right\}_{t=\overline{1, T}}$ is non-stationary if the mean and / or variance is variable over time.

Depending on the characteristics of the average, a non-stationary time series of may be:

- a homogeneous non-stationary time series, in which case:

0 the average of the series is not constant over time, it has a linear trajectory with a positive or negative slope;

- the series is characterized by constant variations from one period to another.

- a series of non-homogeneous non-stationary time, in which case:

0 both average and variance are variable over time;

o the series is characterized by non-constant variations from one period to another.

To test the stationarity of a time series, the following statistical tests are used:

- ADF test (Augmented Dickey-Fuller);

- PP test (Phillips-Perron).

The $t$ test (Student)

$H_{0}$ : the series has a unitary root (is non-stationary);

$t_{\text {test_ADF }}<t_{\text {critic }(1 \%, 5 \%, 10 \%)} \rightarrow$ is rejected $H_{0}$ (series is stationary)

Prob $<$ Relevance_Level $(1 \%, 5 \%, 10 \%) \rightarrow$ is rejected $H_{0}$ (series is stationary).

In order to analyze the evolution in time of the revenues of a company with state-owned capital, it will be used the data from the Income and Expense Budget of METROREX S.A. on a 10-year horizon and every quarter.

The Revenue time series is as follows:

\begin{tabular}{|l|l|}
\hline Year/Quarter & Revenue (thousands lei) \\
\hline $2007 \mathrm{Q} 1$ & 124162.5824190487 \\
\hline $2007 \mathrm{Q} 2$ & 121830.3564447934 \\
\hline $2007 \mathrm{Q} 3$ & 149069.5202375271 \\
\hline $2007 \mathrm{Q} 4$ & 133564.4408986309 \\
\hline $2008 \mathrm{1} 1$ & 152159.2502677935 \\
\hline $2008 \mathrm{Q} 2$ & 169822.9430267043 \\
\hline $2008 \mathrm{Q} 3$ & 138791.5493957481 \\
\hline $2008 \mathrm{Q} 4$ & 141448.4673097541 \\
\hline $2009 \mathrm{Q} 1$ & 139826.4564389078 \\
\hline $2009 \mathrm{Q} 2$ & 114276.2584948338 \\
\hline $2009 \mathrm{Q} 3$ & 116463.8746693226 \\
\hline $2009 \mathrm{Q} 4$ & 125282.7703969358 \\
\hline $2010 \mathrm{Q} 1$ & 124966.0547784584 \\
\hline $2010 \mathrm{Q} 2$ & 127358.3081327084 \\
\hline $2010 \mathrm{Q} 3$ & 137002.1538544534 \\
\hline $2010 \mathrm{Q} 4$ & 152906.306567713 \\
\hline $2011 \mathrm{Q} 1$ & 150094.2319658395 \\
\hline $2011 \mathrm{2} 2$ & 164550.5501226293 \\
\hline $2011 \mathrm{2} 3$ & 152967.5196799344 \\
\hline $2011 \mathrm{Q} 4$ & 183652.7102315969 \\
\hline $2012 \mathrm{Q} 1$ & 155116.5414363921 \\
\hline $2012 \mathrm{Q} 2$ & 141489.0326087752 \\
\hline
\end{tabular}




\begin{tabular}{|l|l|}
\hline Year/Quarter (contd.) & Revenue (thousands lei) (contd.) \\
\hline $2012 Q 3$ & 173123.536902886 \\
\hline $2012 Q 4$ & 144197.5890519468 \\
\hline $2013 Q 1$ & 170587.9838074871 \\
\hline $2013 Q 2$ & 152844.7173169066 \\
\hline $2013 Q 3$ & 142085.6830118408 \\
\hline $2013 Q 4$ & 139416.7958637656 \\
\hline $2014 Q 1$ & 154083.3072818941 \\
\hline $2014 Q 2$ & 165750.8275678453 \\
\hline $2014 Q 3$ & 184992.3241416051 \\
\hline $2014 Q 4$ & 151189.0610086556 \\
\hline $2015 Q 1$ & 167716.6768345032 \\
\hline $2015 Q 2$ & 187186.3827178873 \\
\hline $2015 Q 3$ & 155910.7766289194 \\
\hline $2015 Q 4$ & 152982.2038186901 \\
\hline $2016 Q 1$ & 168560.2424250711 \\
\hline $2016 Q 2$ & 181323.9874574992 \\
\hline $2016 Q 3$ & 165394.0665293109 \\
\hline
\end{tabular}

The time series graph is as follows:

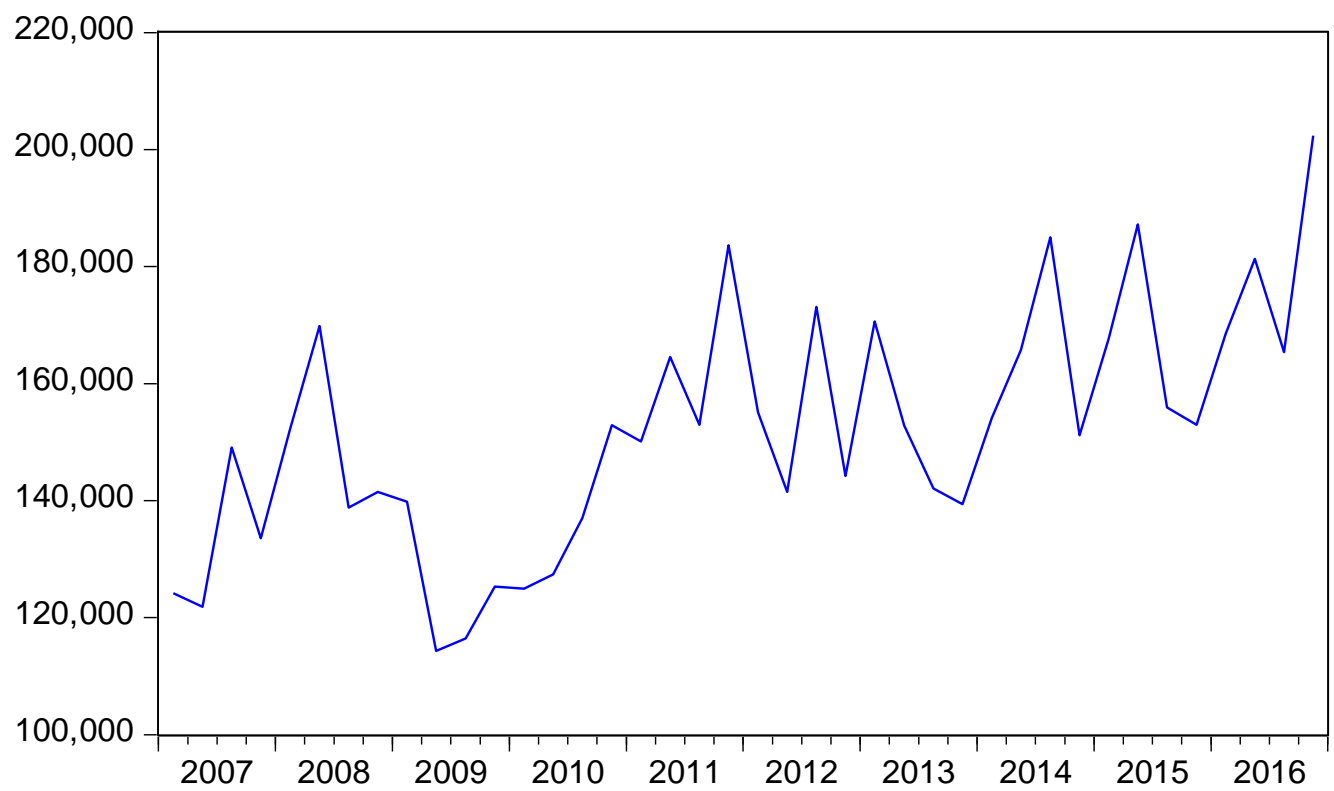

The results of the ADT (Augmented Dickey-Fuller) test for the presented time series (Revenue) are as follows:

Null Hypothesis: VENIT has a unit root

Exogenous: Constant, Linear Trend

Lag Length: 0 (Automatic - based on SIC, maxlag=9)

\begin{tabular}{lccc}
\hline \hline & t-Statistic & Prob.* \\
\hline \hline Augmented Dickey-Fuller test statistic & -4.535271 & 0.0043 \\
\hline Test critical values: & 1\% level & -4.211868 & \\
& $5 \%$ level & -3.529758 & \\
& 10\% level & -3.196411 & \\
\hline \hline
\end{tabular}

*MacKinnon (1996) one-sided p-values. 


\begin{tabular}{lrrrr}
\multicolumn{1}{c}{ Variable } & Coefficient & Std. Error & t-Statistic & Prob. \\
\hline \hline \multicolumn{1}{c}{ VENIT(-1) } & -0.771840 & 0.170186 & -4.535271 & 0.0001 \\
C & 100225.0 & 22664.89 & 4.422039 & 0.0001 \\
@ TREND("2007Q1") & 901.7130 & 288.1934 & 3.128847 & 0.0035 \\
\hline \hline R-squared & 0.365458 & Mean dependent var & 2005.404 \\
Adjusted R-squared & 0.330206 & S.D. dependent var & 19427.81 \\
S.E. of regression & 15899.90 & Akaike info criterion & 22.25982 \\
Sum squared resid & $9.10 \mathrm{E}+09$ & Schwarz criterion & 22.38778 \\
Log likelihood & -431.0664 & Hannan-Quinn criter. & 22.30573 \\
F-statistic & 10.36694 & Durbin-Watson stat & 1.960003 \\
Prob(F-statistic) & 0.000278 & & \\
\hline \hline
\end{tabular}

As you can see $t_{\text {test_ADF }}=-4.535271$ and the associated value $p$ is 0.0043 . Because $t_{\text {test_ADF }}<$ $t_{\text {critic }(1 \%, 5 \%, 10 \%)}$ is rejected $H_{0}$, so the time series is stationary.

Correlogram errors are used to match the ARMA model specification. In order to analyze autocorrelation coefficients and partial autocorrelation coefficients, select option View $\rightarrow$ Correlogram, which is available in the window of the series considered.

The correlogram obtained for the studied variable is as follows:

\begin{tabular}{|c|c|c|c|c|c|c|}
\hline Autocorrelation & Partial Correlation & & $A C$ & PAC & Q-Stat & Prob \\
\hline$.||^{* * *} \mid$ & $.\left.\right|^{* * *} \mid$ & 1 & 0.469 & 0.469 & 9.4775 & 0.002 \\
\hline$.||^{* * *} \mid$ & $.||^{* *} \mid$ & 2 & 0.406 & 0.238 & 16.753 & 0.000 \\
\hline.$|* * *|$ &.$\left.\right|^{*}$. & 3 & 0.386 & 0.175 & 23.504 & 0.000 \\
\hline $.1^{*} . \quad \mid$ & $.^{*} \mid .1$ & 4 & 0.157 & -0.166 & 24.655 & 0.000 \\
\hline.$\left.\right|^{*}$ & .1 .1 & 5 & 0.135 & -0.018 & 25.528 & 0.000 \\
\hline $.1^{*} . \quad \mid$ & $.\left.\right|^{*} . \quad \mid$ & 6 & 0.182 & 0.126 & 27.162 & 0.000 \\
\hline$.\left.\right|^{*} . \quad \mid$ & .1 .1 & 7 & 0.103 & 0.023 & 27.708 & 0.000 \\
\hline$.\left.\right|^{*} . \quad \mid$ & .1 .1 & 8 & 0.094 & -0.021 & 28.170 & 0.000 \\
\hline $.1^{*} . \quad \mid$ & $.\left.\right|^{*} . \quad \mid$ & 9 & 0.165 & 0.084 & 29.636 & 0.001 \\
\hline $.1^{*} . \quad \mid$ & .1 .1 & 10 & 0.075 & -0.033 & 29.955 & 0.001 \\
\hline.$\left.\right|^{*}$ & .1 .1 & 11 & 0.123 & 0.068 & 30.830 & 0.001 \\
\hline .1 .1 & $. * 1 . \mid$ & 12 & 0.019 & -0.154 & 30.852 & 0.002 \\
\hline .1 .1 & $.1^{*} . \quad \mid$ & 13 & 0.070 & 0.101 & 31.153 & 0.003 \\
\hline $.1^{*}$ & $.1^{*}$ & 14 & 0.130 & 0.122 & 32.251 & 0.004 \\
\hline $.1^{*} . \quad \mid$ & .1 .1 & 15 & 0.080 & -0.001 & 32.678 & 0.005 \\
\hline$.^{*} \mid 1$ & $* * *|. \quad|$ & 16 & -0.100 & -0.344 & 33.373 & 0.007 \\
\hline .1 .1 & $.\left.\right|^{*} . \quad \mid$ & 17 & 0.052 & 0.155 & 33.573 & 0.010 \\
\hline.$^{*}|. \quad|$ & $.^{*} \mid .1$ & 18 & -0.098 & -0.075 & 34.308 & 0.012 \\
\hline.$^{*} .1$ & .1 .1 & 19 & -0.136 & -0.007 & 35.781 & 0.011 \\
\hline .1 .1 &.$* 1.1$ & 20 & -0.030 & -0.078 & 35.858 & 0.016 \\
\hline
\end{tabular}

According to the time series correlogram, it can be seen that the autocorrelation function (AC) has the first 7 significant values different from 0 and decreasing. Also, the first 4 values of the partial autocorrelation function (ACP) differ significantly from 0 . It can be concluded that the series will have a MA component with the number of lags (q) equal to at most 7 and that the autoregressive process has an AR component of order $\mathrm{p}=4$.

Analyzing the seasonality of the time series is done as follows: from the View menu of the time series, select the Graph option, then the Seasonal Graph and the seasonality graph is obtained. For the time series presented, the seasonality graph generated by EViews is as follows: 


\section{venit by Season}

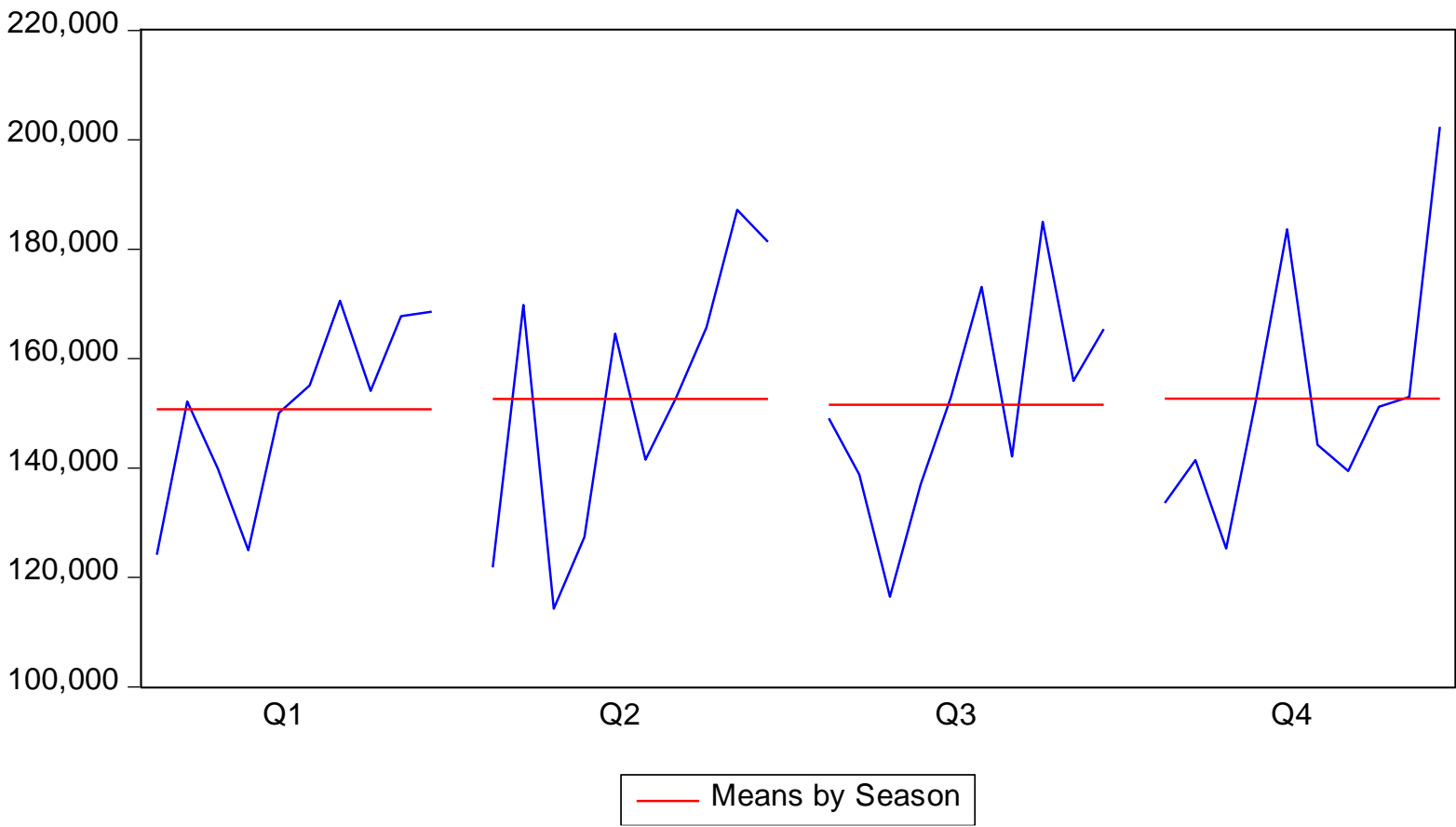

The method of removing from the time series values the trend values to be used is the moving average method. Thus, to adjust the seasonality of the time series, it is selected from the Proc data series window, then Seasonal Adjustment, Moving Average Methods, Ratio to moving - Multiplicative. The adjusted venity series is obtained.

A first equation could be: revenue $\operatorname{ar}(1)$ ar (2) ar (3) ar (4) c. The results of parameter estimation generated with EViews are as follows:

\begin{tabular}{|c|c|c|c|c|}
\hline Variable & Coefficient & Std. Error & t-Statistic & Prob. \\
\hline $\mathrm{C}$ & 160068.5 & 13346.15 & 11.99361 & 0.0000 \\
\hline $\mathrm{AR}(1)$ & 0.386831 & 0.188422 & 2.052998 & 0.0486 \\
\hline $\mathrm{AR}(2)$ & 0.231909 & 0.191494 & 1.211050 & 0.2350 \\
\hline $\mathrm{AR}(3)$ & 0.313735 & 0.191865 & 1.635180 & 0.1121 \\
\hline $\mathrm{AR}(4)$ & -0.191394 & 0.185977 & -1.029131 & 0.3114 \\
\hline R-squared & 0.374317 & \multirow{7}{*}{\multicolumn{2}{|c|}{$\begin{array}{l}\text { Mean dependent var } \\
\text { S.D. dependent var } \\
\text { Akaike info criterion } \\
\text { Schwarz criterion } \\
\text { Hannan-Quinn criter. } \\
\text { Durbin-Watson stat }\end{array}$}} & 154108.2 \\
\hline Adjusted R-squared & 0.293583 & & & 20413.05 \\
\hline S.E. of regression & 17156.88 & & & 22.46643 \\
\hline Sum squared resid & $9.13 \mathrm{E}+09$ & & & 22.68637 \\
\hline Log likelihood & -399.3958 & & & 22.54320 \\
\hline F-statistic & 4.636455 & & & 1.881560 \\
\hline Prob(F-statistic) & 0.004744 & & & \\
\hline Inverted AR Roots & .79 & .47 & $44+.56 \mathrm{i}$ & $-.44-.56 \mathrm{i}$ \\
\hline \multicolumn{5}{|c|}{ Heteroskedasticity Test: White } \\
\hline F-statistic & 0.951225 & \multicolumn{2}{|c|}{ Prob. F(14,21) } & 0.5271 \\
\hline Obs*R-squared & 13.97020 & \multicolumn{2}{|c|}{ Prob. Chi-Square(14) } & 0.4519 \\
\hline Scaled explained SS & 4.658408 & \multicolumn{2}{|c|}{ Prob. Chi-Square(14) } & 0.9900 \\
\hline
\end{tabular}

As we can see, it can be said that the autoregressive model is valid because the F-statistic $=4.636455>$ F critic and Prob(F-statistic $)=0.004744<0,05$. Because the Durbin-Watson test value is 1.881560 and is close to 2 then it can be said that there is no serial correlation between residues. 
The equation thus obtained is:

Revenue $=160068.512989+0.3868309333 *$ Revenue $_{t-1}+0.231909334819 *$ Revenue $_{t-2}+0.313734553$ $884 *$ Revenue $_{t-3}-0.191394355907 *$ Revenue $_{t-4}$

$>\mathrm{F}$ critic and Prob(F-statistic) $=0.011579<0,05$. Because the Durbin-Watson test value is 1.881706 and is close to 2 then it can be said that there is no serial correlation between residues.

Another equation could be: revenue ar (1) ma (1) c. The results of estimating the parameters generated with EViews are as follows:

\begin{tabular}{lrlll}
\hline \hline \multicolumn{1}{c}{ Variable } & Coefficient & Std. Error & t-Statistic & Prob. \\
\hline \hline \multicolumn{1}{c}{ C } & 163524.9 & 17136.16 & 9.542679 & 0.0000 \\
MR(1) & 0.881660 & 0.129015 & 6.833761 & 0.0000 \\
MA(1) & -0.506109 & 0.216197 & -2.340956 & 0.0249 \\
\hline \hline R-squared & 0.355531 & Mean dependent var & 152624.6 \\
Adjusted R-squared & 0.319727 & S.D. dependent var & 20511.67 \\
S.E. of regression & 16917.75 & Akaike info criterion & 22.38392 \\
Sum squared resid & $1.03 E+10$ & Schwarz criterion & 22.51188 \\
Log likelihood & -433.4864 & Hannan-Quinn criter. & 22.42983 \\
F-statistic & 9.929962 & Durbin-Watson stat & 1.962302 \\
Prob(F-statistic) & 0.000368 & & & \\
\hline \hline & Inverted AR Roots & .88 & & \\
Inverted MA Roots & .51 & & \\
\hline \hline
\end{tabular}

As we can see, it can be said that the autoregressive model is valid because F-statistic $=9.929962>\mathrm{F}$ critic and Prob(F-statistic) $=0.000368<0,05$. Because the Durbin-Watson test value is 1.962302 and is close to 2 then it can be said that there is no serial correlation between residues.

Another equation could be: revenue ar(1) ar (2) ar (3) ma (1) ma (2) c. The results of the estimation of parameters generated with EViews are as follows:

\begin{tabular}{crlrl}
\hline \hline \multicolumn{1}{c}{ Variable } & Coefficient & \multicolumn{1}{c}{ Std. Error } & t-Statistic & Prob. \\
\hline C & 160287.0 & 13605.79 & 11.78079 & 0.0000 \\
AR(1) & -0.082614 & 0.379227 & -0.217848 & 0.8290 \\
AR(2) & 0.150075 & 0.339450 & 0.442111 & 0.6615 \\
AR(3) & 0.503365 & 0.213167 & 2.361363 & 0.0247 \\
MA(1) & 0.484129 & 0.409589 & 1.181986 & 0.2462 \\
MA(2) & 0.275258 & 0.386167 & 0.712796 & 0.4813 \\
\hline \hline R-squared & 0.392751 & Mean dependent var & 153552.9 \\
Adjusted R-squared & 0.294807 & S.D. dependent var & 20408.93 \\
S.E. of regression & 17138.55 & Akaike info criterion & 22.48344 \\
Sum squared resid & $9.11 E+09$ & Schwarz criterion & 22.74467 \\
Log likelihood & -409.9437 & Hannan-Quinn criter. & 22.57554 \\
F-statistic & 4.009978 & Durbin-Watson stat & 1.934535 \\
Prob(F-statistic) & 0.006383 & & & \\
\hline \hline Inverted AR Roots & .83 & -.46+.63i & -.46-.63i & \\
Inverted MA Roots & $-.24+.47 \mathrm{i}$ & -.24-.47i & \\
\hline \hline
\end{tabular}

As we can see, it can be said that the autoregressive model is valid because F-statistic $=4.009978>\mathrm{F}$ critic and Prob(F-statistic) $=0.006383<0,05$. Because the Durbin-Watson test value is 1.934535 and is close to 2 then it can be said that there is no serial correlation between residues.

Another equation could be: revenue ar (1) ar (2) ar (3) ar (4) ma (1) ma (2) ma (3) c. The results of estimating the parameters generated with EViews are as follows: 


\begin{tabular}{crrrr}
\hline \hline \multicolumn{1}{c}{ Variable } & Coefficient & \multicolumn{1}{c}{ Std. Error } & t-Statistic & Prob. \\
\hline C & 159478.5 & 13768.20 & 11.58310 & 0.0000 \\
AR(1) & 0.338820 & 1.128363 & 0.300276 & 0.7662 \\
AR(2) & -0.498684 & 0.431416 & -1.155924 & 0.2575 \\
AR(3) & 0.710397 & 0.501375 & 1.416898 & 0.1675 \\
AR(4) & 0.005560 & 0.738372 & 0.007530 & 0.9940 \\
MA(1) & 0.059988 & 1.199182 & 0.050024 & 0.9605 \\
MA(2) & 0.937647 & 0.061490 & 15.24875 & 0.0000 \\
MA(3) & -0.067818 & 0.931639 & -0.072794 & 0.9425 \\
\hline \hline R-squared & 0.453953 & Mean dependent var & 154108.2 \\
Adjusted R-squared & 0.317441 & S.D. dependent var & 20413.05 \\
S.E. of regression & 16864.67 & Akaike info criterion & 22.49696 \\
Sum squared resid & $7.96 E+09$ & Schwarz criterion & 22.84885 \\
Log likelihood & -396.9453 & Hannan-Quinn criter. & 22.61978 \\
F-statistic & 3.325378 & Durbin-Watson stat & 1.955729 \\
Prob(F-statistic) & 0.010523 & & & \\
\hline \hline Inverted AR Roots & .81 & -.01 & -.23-.91i & $-.23+.91 i$ \\
Inverted MA Roots & .07 & -.07-.97i & -.07+.97i \\
\hline \hline
\end{tabular}

As we can see, it can be said that the autoregressive model is valid because F-statistic $=3.325378>\mathrm{F}$ critic and Prob(F-statistic) $=0.010523<0,05$. Because the Durbin-Watson test value is 1.955729 and is close to 2 then it can be said that there is no serial correlation between residues.

\section{Conclusions}

According to the time series correlogram, it can be seen that the autocorrelation function (AC) has the first 7 significant values different from 0 and decreasing. Also, the first 4 values of the partial autocorrelation function (ACP) differ significantly from 0 . It can be concluded that the series will comprise a MA component with the number of lags (q) equal to at most 7 and that the autoregressive process has an AR component of order $\mathrm{p}=4$.

Several autoregressive patterns can be built, we have generated 3 such models. From the data generated by EViews following the estimation of the five equation parameters, it can be observed that all autoregressive models are statistically valid (F-statistic $>\mathrm{F}$ critical and prob (F-statistic) $=<0,05$ ).

To choose the best model, it is chosen according to the classical criterion, namely the highest value of the regression coefficient $R^{2}$ (which is 0.453953 ) for the 5th model, respectively the lattest, but also because it has all the coefficients of the parameters significantly different from 0 . The selected model is ARMA (4.3).

The equation thus obtained is:

Revenue $=159478.5+0.338820 *$ Revenue $_{t-1}-0.498684 *$ Revenue $_{t-2}+0.710397 *$ Revenue $_{t-3}-$ $0.005560 *$ Revenue $_{t-4}+0.059988 * \varepsilon_{t}+0.937647 * \varepsilon_{t-1}-0.067818^{*} \varepsilon_{t-2}$

\section{References}

Voineagu, V. Boboc, C., Ghita, S., Titan, E. (2007). Statistica : baze teoretice si aplicatii, Editura Economică, București, 153160.

Tudorel, A., Regis, B. (2008). Econometrie, Editura Economică, București, 335-381.

Stancu, S., (2011). Econometrie. Teorie și aplicații utilizând EViews, Editura ASE, București, 377-444.

Tudorel, A., Stancu, S., Iacob, A. I., Tușa, E., (2008). Introducere în econometrie utilizând Eviews, Editura Economică, București, 189-209. 